\title{
Cidadãos e cidadãs na cidade grega clássica. Onde atua o gênero?
}

\author{
Violaine Sebillotte Cuchet ${ }^{[1]}$
}

\begin{abstract}
Resumo
O gênero, enquanto categoria analítica, combinado aos trabalhos pioneiros dos anos 1980 sobre o caráter misto da maioria das práticas cívicas e do léxico da cidadania, convidam-nos a traçar um quadro da cidadania grega clássica (nomeadamente ateniense) bastante afastado da definição dada por Aristóteles no livro III das Politika (1275b17-20). O presente artigo busca distinguir, por um lado, o que diz respeito ao regime democrático, propriamente dito - e, de forma mais geral, à abordagem que visa descrever regimes políticos (na Grécia antiga ou alhures) -, do que diz respeito, por outro lado, às práticas cívicas dos politai - práticas “políticas”, em termos gregos -, nas quais, embora diferenciados em suas funções, mulheres e homens são solidários.
\end{abstract}

Palavras-chave: Atenas, cidadania, gênero.

\section{Ciudadanos y ciudadanas en la ciudad griegra clásica. ¿Dónde actua el género?}

\section{Resumen}

El género, en cuanto categoría analítica, combinado con los trabajos pioneros de los años 1980 acerca del carácter mixto de la mayoría de las prácticas cívicas y del léxico de la ciudadanía, nos invitan a trazar un cuadro de la ciudadanía griega clásica (sobretodo ateniense) muy alejado de la definición hecha por Aristóteles en el libro III de las Politika (1275b17-20). El presente artículo pretende distinguir, por un lado, lo que dice respecto propiamente al régimen democrático - y, de forma más general, al enfoque que objetiva describir los regímenes políticos (en Grecia o en otra parte) - de lo que se refiere, por otro lado, a las prácticas cívicas de los politai - prácticas “políticas", en términos griegos -, en las cuales aunque diferenciados en sus funciones mujeres y hombres son solidarios.

Palabras-clave: Athènes, citoyenneté, genre.

\section{Male and female citizens in the greek classical city. What gender do to the po- litical body?}

\begin{abstract}
Gender as a category of analysis, combined with the results of the pionneering scholarship of the eighties about the mixed feature of many civic practices and of the male and female vocabulary of citizenship, invite us to give a picture of Ancient Greek citizenship quite different from the definition given in Aristotle's Politika (1275b77-20). This paper distinguishes between what is linked to democratic as a political regime, and more broadly, to the point of view of political regimes' observations (in Ancient Greece or elsewhere) and what is linked to concrete civical practices - political in Greek words - where the politai, even with different functions, are, male and female, all joined together.
\end{abstract}

Keywords: Athens; citizenship; gender.

\section{Citoyens et citoyennes dans la cité grecque classique. Où joue le genre?}

\section{Résumé}

L'outil du genre, combiné aux travaux pionniers des années 1980 sur le caractère mixte de la plupart des pratiques civiques et du lexique de la citoyenneté, invitent à dresser un tableau de la citoyenneté grecque classique (surtout athénienne) assez éloigné de la définition donnée par Aristote dans le livre III des Politika (1275b17-20). Le présent article entend distinguer entre d'une part ce qui relève du régime démocratique proprement dit et, plus généralement, du point de vue visant à décrire des régimes politiques (en Grèce ancienne ou ailleurs) et d'autre part ce qui relève des pratiques civiques - pratiques «politiques » en termes grecs - des politai où, quoique distingués dans leur fonction, femmes et hommes sont solidaires.

Mots-clés: Athènes; citoyenneté; genre. 
$\mathrm{T}$ odos nós aprendemos, na maioria das vezes, durante nossos estudos de história, que a ideia moderna de cidadania nasceu na Atenas clássica, antes de que a ciuitas e as ciuites da Roma republicana se impusessem. Ao mesmo tempo, todos nós descobrimos que a política ou, em outras palavras, o fato de compartilhar, participar e decidir - de forma mais ou menos coletiva, enquanto cidadãos - um destino comum nascera nas práticas que os Gregos designavam com a expressão ta politica, "os assuntos da pólis", nome grego para a cidade (ciuitas) ${ }^{2}$. Estas afirmações não são fruto do acaso. Provêm diretamente da transmissão de uma tradição que se ampara, principalmente, no tratado Ta Politika, de Aristóteles, e, mais especificamente, num trecho muito conhecido do livro III, que contém uma definição sintética do cidadão: "A natureza do cidadão emerge com clareza dessas considerações: quem tem a possi-

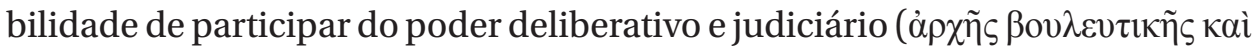

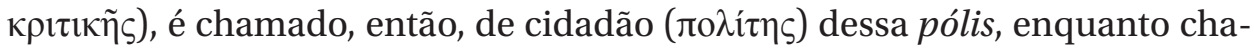

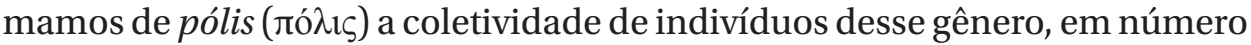
suficiente para viverem, numa palavra, em autarquia". ${ }^{3}$ existência de um léxico antigo e diretamente traduzível em termos contemporâneos (politika/política-politics; politai-civites/cidadania-citizenship; demokratia/democracia-democracy; respublica/república-republic) cria uma ilusão de correspondência entre o fato político tal como existia na Antiguidade clássica e o fato político que se conhece no mundo contemporâneo, ou entre a cidadania antiga e a cidadania contemporânea. A Antiguidade não fornece, portanto, um terreno adequado para a aplicação de uma definição contemporânea do político. ${ }^{4} \mathrm{O}$ propósito do presente artigo é examinar a pólis clássica - e, em especial, Atenas -, incluindo, nela, as mulheres. A demonstração parte da hipótese de que a categoria analítica de gênero permite restituir uma compreensão do político e da cidadania antiga, obviamente, bastante afastada do que hoje se entende por esses vocábulos, embora mais próxima daquilo que os Antigos praticavam.

Sem que qualquer regra tenha sido decretada, era tácito - pelo menos, para os Gregos da Antiguidade - que a presença em assembleias cívicas ficava reservada aos adultos selecionados, todos homens. Os textos à nossa disposição e os registros das decisões coletivas, com efeito, só mencionam homens como atores das discussões e decisões. Como lembrado por Vincent Gabrielsen, o

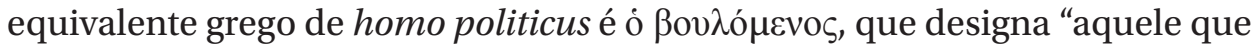

\footnotetext{
2Sobre o sentido a ser atribuído às politika e as interpretações do político (em comparação com a política), ver o recente dossiê coordenado por Vincent Azoulay (2014a), e seu artigo (Azoulay, 2014b) em especial, p. 691-697. O Dictionnaire historique de la langue française (Rey, 1998) indica s.v. "politique": "Adquire valor neutro (o político e o social) para designar o que diz respeito ao governo das sociedades (1927)".

${ }^{3}$ Aristóteles, Política, III, 1275b17-20. Já em 1892, Szanto (1892, p. 2-7) fundamentava a sua análise dos decretos de concessão de cidadania produzidos pelas cidades gregas sob a autoridade da definição fornecida por Aristóteles, o que é apontado, não sem malícia, por Glotz (1894). Sobre a tradição historiográfica, ver Müller (2014, p. 750, nota 31).

4Por exemplo, o Dictionnaire des sciences économiques et sociales (2012), propõe, na p. 298: "Numa democracia, o poder político emana dos cidadãos, agrupados em nação, e o Estado é o instrumento da nação". Em Atenas, porém, na época clássica, as noções de nação (genos?) e Estado são de difícil tradução, sendo a sua própria existência objeto de debate. Ver Cohen (2000) e Ismard (2014). No entanto, o fato de a Antiguidade clássica ter servido para pensar a política no sentindo moderno é uma evidência. Ver Rey (1998, s.V. "politique").
} 
propôs o decreto", o qual foi discutido, votado e, em seguida, inscrito numa estela. A pedra, quando existe, deixa, de facto, a marca de uma prática deliberativa e legislativa, que simboliza, para nós, a própria essência do político (Gabrielsen, 2011, p. 245).

Dentre os indivíduos livres das póleis, encontravam-se, no entanto, mulheres. Costuma-se descrever as mulheres aparentadas aos indivíduos que participavam das assembleias, que acabamos de descrever, como colocadas, de forma mais ou menos formal (Vial, 1996), ${ }^{5}$ sob a tutela de um homem: pai, marido, irmão, filho ou, até mesmo, um outro membro masculino de sua família. Em todos os assuntos políticos (ou seja, discutidos nas assembleias coletivas), as mulheres, quando concernidas, viam-se representadas pelo seu кúpı̌c. Caso os assuntos coletivos discutidos em assembleia não lhes concernissem diretamente, as mulheres não eram representadas. Destarte, as mulheres podem ser comparadas, por nós, a alguns cidadãos homens - aqueles que desertavam as assembleias. A diferença é que uns estavam ausentes das assembleias em razão de seu nível de riqueza, sua educação ou sua falta de motivação; e outras, em razão de seu sexo: por razões diferentes, uns e outras ficavam fora do escopo da definição proposta por Aristóteles, no livro III (1275b17-20).

\section{Dentre os indivíduos livres das póleis, encontravam-se, no entanto, mulheres}

A forma de nomear os indivíduos apresenta um outro aspecto, que permite diferenciar as mulheres livres dos homens livres: caberia verificar se a prática vivenciada em Atenas, onde todos os cidadãos atenienses eram designados pelo nome pessoal, seguido do nome do pai e do nome do vilarejo (dêmos) - contrariamente às atenienses, que aparecem nos documentos da prática política com o nome do pai e/ou marido, muitas vezes, sem o nome do dêmos e sem o nome pessoal -, era observada em outras póleis gregas. ${ }^{6}$ As mesmas fontes - ou seja, aquelas surgidas da prática dos tribunais e assembleias - indicam, com efeito, que não era decente designar as mulheres pelos seus nomes pessoais (Schaps, 1977). . As atenienses formavam, dessarte, uma categoria à parte, diferente dos cidadãos, quer estes participassem ou não das assembleias deliberativas e legislativas.

\footnotetext{
${ }^{5}$ A ser lido em contraponto a Foxhall (1996). Em Vial, a kurieia não é apenas formal; em Foxhall, a kurieia é principalmente formal.

${ }^{6}$ Formou-se um grupo de pesquisa para examinar esse ponto: Eurykleia. Celles qui avaient un nom, disponível em http://eurykleia.hypotheses.org/.

${ }^{7}$ Schaps destaca que, nos discursos frente aos tribunais, as cidadãs atenienses eram escrupulosamente nomeadas, não pelo próprio nome, e sim, em relação aos seus parentes de sexo masculino ("minha mãe era filha de X"). Schaps sugere que nomear uma mulher respeitável atraía críticas, nesse contexto. Apenas três categorias de mulheres são designadas pelo nome pessoal: as falecidas - e, portanto, acima de qualquer crítica -, as que tinham má reputação e as parentes daqueles a quem se opõe. Para uma extensão da análise, ver Pantel (1994)
} 
A afirmação de Aristóteles sobre a natureza funcional da cidadania (a participação nas assembleias) e a constatação resultante da leitura dos discursos que emanaram da realização de assembleias judiciárias ou deliberativas, em Atenas e na época clássica, fez com que se escrevesse que a pólis era um "clube de homens". Ainda hoje, a inclusão das mulheres na pólis grega não constitui um problema para a maioria dos especialistas em política. ${ }^{9}$ No entanto, duas grandes orientações foram apresentadas por pesquisadores - e, sobretudo, pesquisadoras -, que contemplam a questão das mulheres (na maioria das vezes, somente em relação a Atenas). Consideremo-nas, sucessivamente.

A primeira considera as mulheres como símbolos do princípio de alteridade - embora esse símbolo possa estar presente nas configurações gregas da masculinidade (Loraux, 1989) -, mulheres essas que representariam, assim, no “imaginário grego", o avesso do político, ou seja, o que não podia relacionar-se ao político ou o que seria o "antipolítico" (Loraux, 1999, p. 45). Convocando o relato feito por Varrão e transmitido por Santo Agostinho, Nicole Loraux expôs o que teria sido o mito original explicativo da exclusão das mulheres (Loraux, 1981, p. 121): $:^{10}$ na "origem" de Atenas, elas teriam sido deliberadamente proibidas de passar os seus nomes aos filhos, de usar o nome de Atenienses e de votar. Essas sanções teriam ocorrido após elas terem unanimamente votado a favor de Atenas e em detrimento de Poseidon, quando da disputa divina pelo território da Ática. As instituições democráticas e o imaginário - coletivo ou cívico - avançariam, dessarte, de mãos dadas, para relembrar a divisão fundamental dos sexos. E a democracia, em sua versão "original", teria se construído sobre o princípio dessa divisão e dessa exclusão. Como formulado por Nicole Loraux: "Não existe nem "cidadã" nem "ateniense", ${ }_{11}$ podendo-se definir, portanto, o cidadão ateniense, simplesmente, como aquele que, por ambos os lados, só tem, por pais, cidadãos: o seu e o da sua mãe" (Loraux, 1981, p. 128, 131). Esta interpretação da pólis ateniense - a primeira democracia aos olhos da tradição ocidental -, atente-se (Mossé, 2013), ${ }^{12}$ é clara: do pensamento mítico até Aristóteles, tudo parece convergir para destacar a evidência da exclusão das mulheres da política (= da pólis) e construir esse campo como especificamente masculino. A insistência no conflito, definido como "constitutivo da definição grega do político" (Loraux, 2005, p. 32) é, nesta, amparado pela importante ideia de que o conflito por excelência é aquele que opõe os sexos. ${ }^{13}$ Encontra-se, no cerne do político, a divisão dos sexos, sinal de um conflito naturalmente presente em qualquer sociedade. Por conseguinte, o valor social, psicológico e político do conflito reside na distinção

\footnotetext{
8"Porque ter associado, num mesmo estudo, o destino de escravos e o de mulheres? Porque a pólis grega, em seu modelo clássico, definia-se por uma dupla recusa: recusa da mulher, a pólis grega é um 'clube de homens', recusa do escravo, ela é um 'clube de cidadãos'." (Vidal-Naquet, 1991, p. 269)

${ }^{9} \mathrm{O}$ recente dossiê de Azoulay (2014a) não o aborda.

${ }^{10}$ Varrão, citado por Santo Agostinho, Cidade de Deus, 18, 9.

"Nota do tradutor: Adjetivo de dois gêneros em português. Leia-se, aqui, no gênero feminino.

${ }^{12}$ Notar-se-á, em particular, o papel de Gustave Glotz na reabilitação da democracia ateniense, assimilada à república (trata-se da III República), (Mossé, 2013, p. 156).

${ }^{13} \mathrm{~A} \mathrm{Ao}$ estudo da pólis una, sucedeu-se a reflexão a respeito da divisão dos sexos, e (que) a divisão dos sexos introduziu a pólis, sub-repticiamente, como como pólis dividida" (Loraux, 1997, p. 24). Ver, a este respeito, Cuchet (2012).
} 
e oposição entre homens e mulheres, e não entre amigos e inimigos. ${ }^{14}$ No horizonte dessa proposta, notar-se-á a sensível ligação traçada entre distinção de sexo e regime democrático. Nunca é demais repetir: a tão celebrada autonomia dos democratas atenienses baseia-se na distinção, no âmbito da cidadania, entre homens e mulheres (Kamen, 2013a). A análise da diferenciação por sexo não pode ser feita sem que se leve em conta o regime político que a produz, no caso, a democracia ateniense, e o círculo social ao qual se destina essa diferenciação. ${ }^{15}$

Na segunda proposta, os pesquisadores descrevem as atenienses como "cidadãs", entre aspas, ou seja, indivíduos que participam da política, mas em menor medida. Entende-se que o político designa, então, a prática cívica - participação nas atividades cívicas e pertencimento a uma comunidade, considerada como bem comum. Neste caso, costuma-se, numa ótica acadêmica e pedagógica, diferenciar os níveis de participação na vida cívica. Assim, Claude Mossé identifica, para os gregos das póleis, os diferentes "planos de sua vida comum": o religioso, o militar e o político, "propriamente dito" (Mossé, 1993, p. 49-64). Essa corrente de pesquisa baseia-se numa abordagem de história social, assim como na ideia de que cada um desses planos deve ser articulado com os demais. Após ter deixado de lado a participação econômica, a pesquisa, renovada graças a jovens pesquisadores - menos marcados pelo esforço finleysiano de separar a pólis antiga de uma perspectiva demasiadamente materialista -, atrela-se mais a ela, atualmente. ${ }^{16}$ Essa abordagem busca descrever a democracia antiga, sobretudo grega, em suas práticas, mais do que em suas definições teóricas, ainda que nativas. Embora ninguém refute a exclusão das mulheres das assembleias políticas, os pesquisadores que trabalham nessa direção dão mais ênfase à variedade de modos de se praticar a vida cívica. Ao decidirem não se focarem apenas nas funções deliberativas e judiciárias descritas por Aristóteles, no Livro III (1275b17-20) das Politika, eles tomam parte na busca por um novo modo de definir o político, questionando a evidência de que as assembleias cívicas teriam sempre sido os locais de governança das pólis. ${ }^{17}$ É para esta abordagem que eu gostaria de atentar, afim de destacar as atuais problemáticas desses trabalhos, numa perspectiva de gênero.

\footnotetext{
${ }^{14}$ Nesse sentido, a análise do conflito como constituinte do político se fundamenta, na obra de Nicole Loraux, numa inspiração tanto antropológica quanto psicanalítica, alheia, parece-me, à discussão de Carl Schmitt a respeito da oposição amigo/inimigo, que Azoulay (2014b, p. 607-700) introduz em sua própria análise do político. Azoulay mobiliza, para tal, uma outra figura do conflito, a dos Tiranicídeos (Azoulay, 2014c, p.18-19). ${ }^{15}$ Claudine Leduc foi a única a ter pesquisado, no âmbito da história da pólis grega, esse vínculo entre distinção dos sexos e regime democrático. Ver, destarte, Leduc (1994; 1998a), com a análise da passagem entre uma sociedade "estruturada em lares" e uma "sociedade política" (1998a, p. 185-186) e a questão da "condição pessoal" da mãe (1998a, p. 196). Ver, também, Leduc (1998b)..

${ }^{16}$ É significativo que o capítulo do livro de Deborah Kamen dedicado às cidadãs de Atenas atente, em primejro lugar, para a sua capacidade econômica (direito de possuir terras, herdar - enquanto tias ou irmãs, mais do que enquanto filhas -, administrar bens, trabalhar para ganhar a vida), antes de se interessar pela sua posição na religião, nos rituais e nas fratrias. Ver Kamen (2013b, p. 87-96).

17Tomemos, dentre outros, o exemplo dos trabalhos de Leduc (1994, p. 52): "Tal qual foi forjado por Aristóteles no livro III da Política, o conceito de cidadania é recente e limitado. Quando o cidadão é definido pelo exercício coletivo do poder, só há cidadãos, "no sentido absoluto do termo", nas pólis que aplicam a democracia, sob alguma de suas quatro formas. Mas acredito que a noção de cidadania, na região grega, é infinitamente mais ampla. A "cidadania” é, em suma, sob diferentes apelações, a participação nos אoเvó, a todas as atividades que os ä $\alpha \delta \rho \varepsilon \varsigma$ praticam juntos, dentro e fora do território, em tempo de paz como em tempo de guerra. Ser "cidadão" é fazer parte da massa quantitativa e quantificável - do $\varpi \lambda \tilde{\eta} \theta$ o de Aristóteles - de pessoas que se reúnem para realizar, coletivamente, atos, práticas e rituais, sendo essa coletividade atuante o que consti-

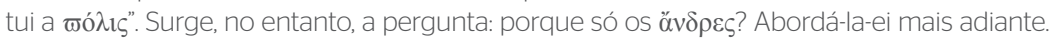




\section{A categoria analítica de gênero}

A partir dos anos 2000, o gênero afigurou-se como uma ferramenta heurística de primeiro plano..$^{18}$ De modo geral, o gênero, usado como categoria analítica - em outras palavras, como ferramenta epistemológica, não raro, sob a forma de uma nova interrogação - permitiu questionar a ideia de que qualquer sociedade se fundamentava numa cesura significativa, obrigatória e necessária, que havia sempre separado mulheres e homens em dois grupos homogêneos e radicalmente opostos.

Os estudos sobre o gênero mostraram, de fato, que a diferenciação entre homens e mulheres resultou de uma escolha cultural: a natureza não distingue meninos e meninas, distribuindo, antes, de forma aleatória e necessária, características cuja combinação produz indivíduos de aparência variada. Embora a distinção entre macho e fêmea não seja evidente em 1,7\% dos nascimentos, o é, no entanto, nos demais $98,3 \%$ dos nascimentos, conforme escolha feita pela imensa maioria das sociedades - a de dividir os recém-nascidos em duas categorias e estabelecer a função de procriação como critério de diferenciação. Esta diferenciação é pertinente por razões estatísticas (a frequência de distribuição das características sexuais), políticas e sociais (a preocupação com a procriação) e/ou culturais (os usos linguísticos e simbólicos), mas é importante lembrar que não tem, em si, qualquer pertinência: não constitui, em si mesma, a sua razão de ser. Ela não é uma "lei natural", e sim uma lei cultural.

Dizer que "mulheres e homens pertencem a duas categorias homogêneas e distintas" não pode ser uma hipótese fundamentada na natureza, pois podemos dizer, igualmente, que "mulheres e homens pertencem à mesma categoria", a dos seres humanos. A diferença entre as duas hipóteses explica-se, é fácil de entender, por uma diferença de ponto de vista: ora se escolhe o critério da procriação (a função biológica, identificada pela distinção de anatomias), ora o da espécie (humana, animal ou vegetal). Os estudos de gênero destacaram, assim, o caráter político e cultural da diferenciação menina/menino.

Ao aproximarem a distinção sexo/gênero da distinção racial, os estudos de gênero também insistiram no aspecto discriminante da marca de gênero. Todos concordam em dizer que a distinção branco/negro resulta de um discurso político e ideológico (a racialização dos indivíduos), que produz, infelizmente, efeitos sociais discriminantes: brancos e negros formam duas categorias distintas, pertinentes para as estatísticas das prisões americanas e para a cartografia das grandes cidades da América do Norte e da Europa. Todos concordam, também, em dizer que a cor da pele é um resultado multifatorial, relacionado à quantidade de melanina produzida por cada indivíduo. A cor da pele diferencia os indivíduos, como o fazem o tamanho ou a cor dos cabelos, ou seja, de acordo com uma paleta mais ou menos extensa, em função da hereditariedade, das

${ }^{18}$ No tocante à descrição dessa categoria analítica, devo muito às várias discussões travadas com Sandra Boehringer e Marianne Blidon. 
regiões e das épocas. Essa variedade de características físicas realça o caráter arbitrário e cultural da binariedade branco/negro.

No tocante à distinção dos sexos, a diferenciação não remete à cor da pele, nem ao tamanho, e sim à divisão funcional traçada entre aqueles que engendram e aquelas que dão a luz. A categorização binária que opõe mulheres e homens não é tanto, dessarte, uma questão de anatomia (as variáveis são grandes na anatomia), e sim uma questão de sexualidade. No entanto, como sempre existem indivíduos estéreis, não se pode dizer que a complementaridade funcional entre homens e mulheres seja uma lei da natureza. Ainda que guardemos o critério da função cumprida pelos indivíduos na procriação, a distinção dos sexos é, de fato, uma convenção cultural: alguns homens não procriam e algumas mulheres não têm filhos.

A abordagem introduzida por essa ferramenta heurística, que é o gênero, constitui, ao contrário, uma abordagem de desconstrução das pressuposições relativas ao ideal de complementaridade (engendramento/nascimento) entre mulheres e homens, não raro, amplamente compartilhadas (estereótipos). A ferramenta é heurística no sentido em que permite, tão logo o seu raciocínio

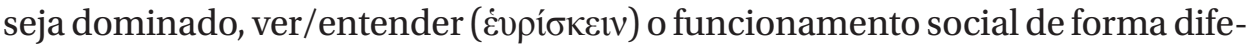
rente, em relação à sua percepção anterior. É tão interessante e útil conduzir uma desconstrução das pré-concepções a respeito de mulheres e homens nos discursos dos modernos, ou seja, nas interpretações apresentadas pela tradição erudita, desde a formação das diferentes disciplinas, quanto nos discursos dos antigos. De fato, cada vez que um analista descreve uma realidade social, ele utiliza categorias de discurso e mobiliza diferenciações. Porém, cada segmentação social obedece a uma lógica funcional, tanto mais difícil de identificar quanto se supõe evidente e natural. A distinção entre brancos e negros pode servir para justificar uma dominação econômica e política (racismo), bem como para identificar as discriminações que se busca combater (affirmative action). A distinção entre ricos e pobres pode servir para realçar as injustiças sociais ou pode ser apresentada como uma invariante, que invalidaria qualquer política de redistribuição. A mesma pergunta pode ser colocada em relação à diferenciação dos sexos: por quê razão se segmenta a humanidade entre homens e mulheres? Para justificar a distribuição dos papéis sociais? Para denunciar desigualdades?

Essas perguntas podem ser feitas às nossas sociedades contemporâneas, assim como podem - e devem -, também, ser feitas aos documentos que nos informam a respeito dos homens e mulheres do passado. Por que razões os antigos gregos diferenciavam os homens das mulheres, quando assim procediam? Em que contexto o faziam? Para diferenciar quais homens e quais mulheres? Um(a) historiador(a) que se depara, hoje em dia, com discursos a respeito "das mulheres" - mais frequentemente entendidas como categoria social homogênea do que os homens - já não pode, numa época em que o gênero logrou se impor como uma ferramenta de análise pertinente no âmbito das ciências sociais (Laufer; Rochefort, 2014), considerar esses discursos e expressões como evidências. Ele ou ela deve questionar a finalidade desses 
discursos e categorizações, para ser capaz de descrever com maior precisão a forma como os indivíduos viviam em sociedade. É guardando essas perguntas em mente que podemos, hoje, retomar a questão da cidadania clássica e da pólis, considerada como um "clube de homens", e visitar o laboratório da Grécia antiga com novos instrumentos, para novas medições.

\section{Reler Aristóteles}

Seguindo a análise proposta por Josine Blok quando de seminários em Paris, em 2011, ${ }^{19}$ Aristóteles não teria descrito, em sua definição do livro III, ${ }^{20}$ uma realidade observada - é cidadão quem participa das assembleias -, propondo, antes, uma definição teórica, que teria a vantagem de reduzir as diferenças entre as práticas das diferentes póleis, no intuito de produzir uma espécie de denominador comum daquilo que constitui, fundamentalmente, a cidadania. A definição do livro seria, portanto, o resultado de um raciocínio intelectual que teria buscado dar uma definição da cidadania aplicável a todos os tipos de cidades gregas, apesar das variações observadas no âmbito dessas póleis. De fato, Aristóteles aponta, também, que "na prática" ou "nos costumes", $\pi \rho \varsigma_{\varsigma}$

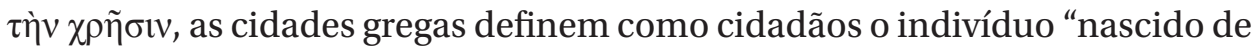
dois pais cidadãos ( $\pi \circ \lambda i ́ \tau \alpha$ ) , e não de um só, pai ou mãe". ${ }^{21}$ Às vezes, algumas póleis exigiam a descendência de pais cidadãos por duas ou três gerações. ${ }^{22}$

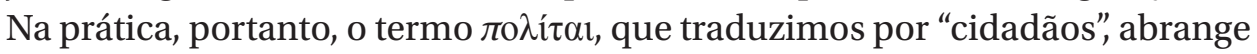
homens e mulheres. O termo "cidadão", empregado, não raro, no masculino sin-

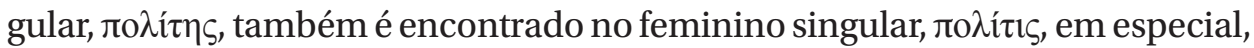

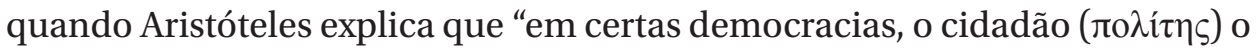
é em função de sua mãe (

Por conseguinte - e continuo seguindo, aqui, a análise de Josine Blok -, a definição minimalista do livro III $^{24}$ não reflete o que é praticado nas póleis, refletindo, antes, o único elemento de praxe política comum a todas as formas de póleis: a participação exclusiva de homens, os $\pi$ o $\lambda i ́ \tau \alpha \iota$ - no masculino -, nas assembleias deliberativas e judiciárias. Mas, na prática, os cidadãos não se definiam por essa função: muitos não participavam das assembleias e não deixavam, contudo, de ser considerados como cidadãos, inclusive nas póleis ditas democráticas. De fato, o cidadão era, antes de mais nada, membro de uma comunidade ( $p o ́ l i s$ ). Suas diferentes funções cívicas nunca eram apli-

\footnotetext{
${ }^{19}$ Há pouco menos de dez anos, os trabalhos de Josine Blok vêm descontruindo o que os historiadores identificaram (na obra de Aristóteles) como a cidadania grega. Ver Blok (2005), e as duas palestras realizadas nos dias 11 e 25 de janeiro de 2011, no Instituto Nacional de História da Arte em Paris, durante o meu seminário, com o título: "Définitions de la citoyenneté: proposition de révision" e "Pratiques de la citoyenneté: descendance, timai et archai". Essas palestras serviram como preparação para a publicação de sua obra: Blok (no prelo). Procedendo assim, Josine Blok prolonga toda uma corrente de pesquisa, que buscou primeiramente estudar a posição das mulheres nos cultos cívicos. A guisa de exemplo, Osborne (2000).

${ }^{20}$ Aristóteles, Po/ítica, III, 1275b17-20.

${ }^{21}$ Aristóteles, Política, III, 1275b21-22.

${ }^{22}$ Aristóteles, Política, III, 1275b23-25.

${ }^{23}$ Aristóteles, Política, III, 1278a28.

${ }^{24}$ Aristóteles, Política, III, 1275b17-20.
} 
cáveis a uma pólis outra do que a comunidade da qual era membro, a menos que acordos específicos tivessem sido firmados entre a sua pólis e as demais. Antes da função deliberativa e judiciária, o indivíduo precisava, portanto, ter sido designado como cidadão pelos seus pares.

\section{É guardando essas perguntas em mente que podemos, hoje, retomar a questão da cidadania clássica e da pólis, considerada como um "clube de homens", e visitar o laboratório da Grécia antiga com novos instrumentos, para novas medições}

Como apontado por Josine Blok, quando surgia uma contestação de cidadania, a participação nas assembleias - de direito ou efetiva - nunca era convocada como critério de julgamento. Somente os critérios de filiação e reconhecimento social eram convocados. A participação nas assembleias - de direito, caso não fosse de fato - era, portanto, apenas um direito ou privilégio resultante de outros critérios. Destarte, é inexato afirmar que, nas práticas sociais das cidades gregas, o cidadão era definido em função da participação nas assem-

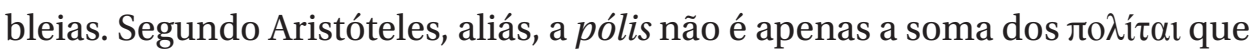
participam ou têm a possibilidade teórica de participar das assembleias; ${ }^{25}$ a pólis é definida, na verdade, por atividades sociais e religiosas compartilhadas: a endogamia cívica e a participação em rituais comuns são indispensáveis à coesão e à autonomia da pólis. ${ }^{26}$ Esta é a ideia que é expressada nos processos de contestação de cidadania, onde a expressão dominante, bem analisada por Josine Blok, é a de "participar da pólis", "tomar parte na pólis". ${ }^{27}$ No entanto, a esfera dos rituais cívicos, como as estratégias matrimoniais necessárias para formar cidadãos e dispor de terras que materializem o vínculo com a pólis, além da riqueza, que qualifica os melhores, mobiliza indivíduos de ambos os sexos.

\section{Os termos para nomear cidadãos: função social e pertencimento ao} grupo

A riqueza lexical daquilo que chamamos de cidadania antiga torna o debate sobre este fenômeno particularmente complexo. Como destacado por Cynthia

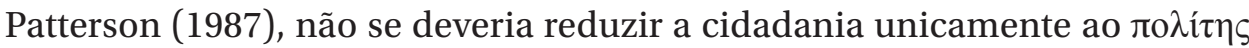

\footnotetext{
${ }^{25}$ Aristóteles, Politica, III, 1275b17-20

${ }^{26}$ Aristóteles, Política, III, 1280b30-1281a9

${ }^{27}$ Blok, palestras de 11 e 25 de janeiro de 2011, "Définitions de la citoyenneté: proposition de révision" e "Pratiques de la citoyenneté: descendance, timai et archai" no Instituto Nacional de História da Arte, Paris..
} 
utilizado por Aristóteles. ${ }^{28}$ Quando empregado no plural, o termo ло $\lambda$ í $\alpha$ ı pode ser utilizado para designar os cidadãos que tomam decisões em assembleia (somente os homens, portanto), mas pode ser utilizado, também, para designar os habitantes de determinada cidade, homens e mulheres. ${ }^{29} \mathrm{Na}$ maioria das vezes, descreve-se a qualidade de pertencimento à pólis pelo uso do substantivo plural, A $A \tilde{\eta} v \alpha$ เor, que pode designar - dependendo dos contextos - tanto atenienses homens quanto mulheres. ${ }^{30}$ Esse termo, o ethnicon, indica que o pertencimento a uma pólis - o que chamamos, novamente, de cidadania - não pode ser compartilhado além das fronteiras da pólis. Aliás, outros ter-

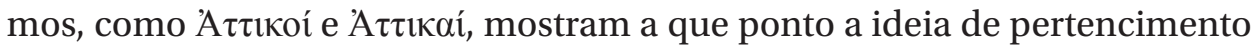
(em função da residência num território definido) é importante para a compreensão do funcionamento do vínculo político na pólis clássica (Patterson, 1987). Cabe ver, também, o que Edouard Will (1979, p. 59) diz a esse respeito: "Termo convencional, pólis é, inevitavelmente, um termo tão abstrato quanto 'Estado'. Por mais que se fale comumente "da pólis arcaica”, só se conhece (e mal!) casos particulares, póleis arcaicas que não podem ser assimiladas umas às outras, embora se possa, numa hipótese plausível, admitir, na maioria dos casos, uma evolução em mesmo sentido, pelo menos, no início."

Na maioria das vezes, descreve-se a qualidade de
pertencimento à pólis pelo uso do substantivo plural,
A 1 ñvatol, que pode designar - dependendo dos
contextos - tanto atenienses homens quanto mulheres

No discurso Contra Neera, o termo empregado para designar aquela que

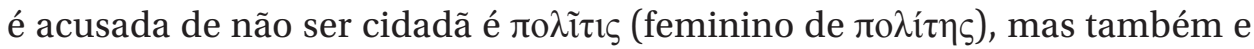

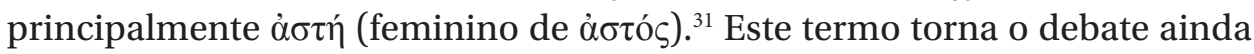
mais complexo e realça a riqueza lexical daquilo que chamamos de cidadania antiga. A Constituição dos Atenienses, do Pseudo-Aristóteles, explica que "durante o mandato de Antídoto, em razão da quantidade de politai, tomou-

\footnotetext{
${ }^{28}$ Caso nos referamos aos termos empregados pelos gregos e busquemos entender as noções às quais nos remetem, somos levados a colocar a questão do pertencimento/participação na comunidade no centro do debate. No entanto, esse pertencimento/participação é formulado como pertencimento/participação no ter-

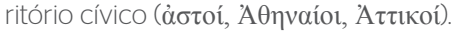

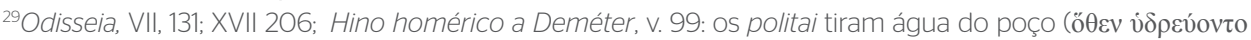

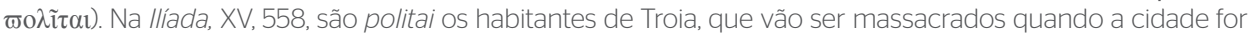
tomada.

30Ver, dentre os decretos do povo, o famosíssimo - por ser raro - exemplo da sacerdotisa de Athená, Niké, selecionada, segundo a inscrição (IG I3 35, entre 448 e 424), "por sorteio, entre todas as atenienses" (em última instância: Blok (2014). Ver, também, as dedicatórias oferecidas pelas atenienses em Delfos, nas quais se designam como Athênaiai (Jacquemin, 2005) e Plutarco, Vida de Péricles, 37. 3, que se referem aos dois pais (pai e mãe) como sendo "atenienses".

31"Essa mulher, pois, que se prostituiu em toda a Grécia e quis se passar por ateniense, ficaria impune, sendo que não é nem ateniense (astê) pelos seus ancestrais, nem cidadã (politis) por decisão do povo" (Apolodoro, Contra Neera 107).
} 
-se a resolução, proposta por Péricles, de não 'compartilhar a pólis' com quem não tivesse nascido de dois astoi”. ${ }^{32}$ Os $\alpha$ otoí, segundo a opinião da maioria dos historiadores, são membros de um espaço perfeitamente identificado, embora não haja perfeita delimitação - o ö́ðv ou a cidade (entendido como pólis). Eles formam uma comunidade de residência e nascimento, no sentido social.

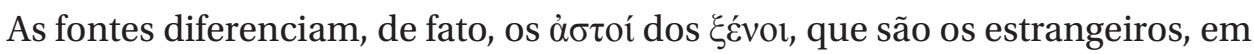
visita na Ática. Segundo os historiadores, a comunidade dos ảotoí, residentes na Ática, é definida de forma mais ou menos ampla: para alguns, como Edward Cohen (2000), os metecos residentes são ảotoí, bem como os escra-

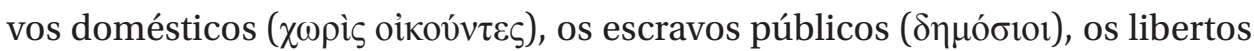

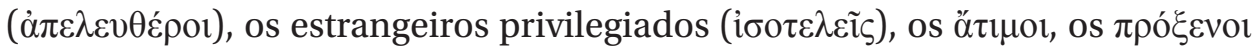

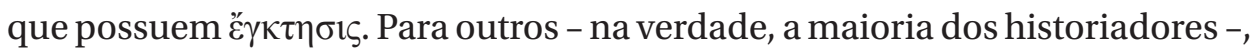
os ảotoí são os atenienses de nascença, todos aqueles que, por sua filiação ate-

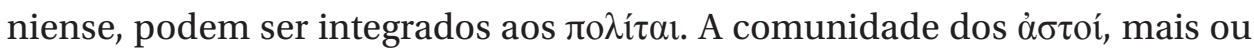
menos ampla, participa das atividades comuns: rituais, exército e finanças, em graus variáveis, que as pesquisas atuais tendem a elucidar.

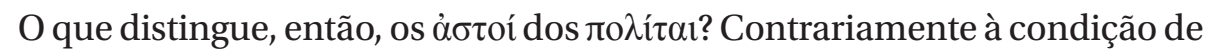

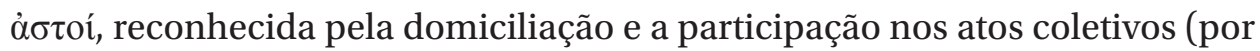

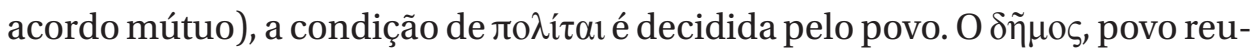
nido em assembleia e composto apenas de cidadãos do sexo masculino, pode, assim, transformar um indivíduo em ateniense, seja por este indivíduo ter sido reconhecido como descendente de pais atenienses desde a infância, seja atuando como se o tivesse sido. Por oposição aos $\dot{\alpha} \sigma \tau$ ó́, os $\pi$ o $\lambda$ í $\alpha$ ı poderiam, portanto, ser descritos como indivíduos que gozam de um reconhecimento cívico pelo povo, reunido em assembleia. Como atua o gênero durante esse processo?

\section{A formação da cidadania: um processo diferenciado para meninas e meninos}

Como todos sabemos, a primeira etapa na formação dos atenienses é o reconhecimento paterno, nos primeiros dias seguintes ao nascimento (Gherchanoc, 2012). Essa decisão diz respeito às crianças, meninas ou meninos, pois se trata de determinar se o recém-nascido é aceito no grupo legítimo do lar. É o cumprimento dessa etapa que permite integrar a criança no grupo dos atenienses "por ancestralidade" ou, em outras palavras, produzir a filiação e o parentesco. Sabe-se que os meninos de três a quatro anos eram, em seguida, apresentados à fratria, uma forma de estabelecer o reconhecimento social da filiação e do pertencimento ao grupo de parentesco. Essa operação foi menos asseverada para as meninas, embora o debate continue aberto. ${ }^{33}$

\footnotetext{
${ }^{32}$ Aristóteles, Constituição dos Atenienses, 26.4.

${ }^{33}$ As fratrias levam em consideração as mulheres, de uma forma ignorada pelos demos: os membros da fratria de Pirro são convidados a dar testemunho de que ele nunca ofereceu uma gamêlia (banquete de casamento) e não introduziu sua filha putativa na fratria (Iseu 3.76). Trata-se do único texto que menciona a introdução de uma menina numa fratria. A apresentação da noiva no momento do casamento, pelo contrário, é frequentemente mencionada. Ver Lambert (1996) e Todd (1997).
} 
Na puberdade, os rituais realizados por meninas e meninos já não são comparáveis: os meninos são apresentados para ingresso, enquanto adultos, na fratria; é o ritual anual, bastante conhecido (se assim se pode dizer), das Apaturias, que consiste na oferenda de uma mecha de cabelo e na partilha de um banquete, o que permite a integração de uma categoria etária, a dos jovens de 16 anos. As meninas, porém, por volta da mesma idade, são frequentemente oferecidas em casamento. $\mathrm{O}$ casamento também ocasiona um banquete de apresentação dos noivos - sem dúvida, na fratria do marido (que pode ser a mesma da esposa, posto que a endogamia cívica é acentuada). A apresentação dos noivos é uma forma de fazer validar, diante de testemunhas, a boa condição dos dois esposos: ambos devem ser ảotó, desde a lei de Péricles, se seguirmos o autor da Athênaiôn Politeia ${ }^{34}$ : "durante o mandato de Antídoto, em razão da quantidade de politai, tomou-se a resolução, proposta por Péricles, de não 'compartilhar a pólis' com quem não tivesse nascido de dois astoi".

Em seguida, são os meninos, e apenas eles, que são inscritos no registro do dêmos (o lexiarchikon grammateion), com 18 anos. Desta vez, a apresentação é realizada diante da assembleia dos demotas, os pares políticos e territoriais do mesmo vilarejo. $\mathrm{O}$ aspecto é menos homogêneo e menos "familiar", mas os jovens continuam precisando manifestar que são ỏotoí, de nascimento legítimo. ${ }^{35}$ É, portanto, a afiliação, acrescida de um reconhecimento público pelos demotas, que permite a integração do jovem ateniense nos corpos deliberativos e executivos e produz a categoria dos $\pi$ o $\lambda i \tau \alpha$, no masculino. A distinção entre homens e mulheres jovens intervém nesse âmbito, o das instituições deliberativas e judiciárias, das responsabilidades administrativas e de comando (’’ $\chi \alpha$ í). O repetido exame (dokimasie) dessa correta condição de ateniense é uma oportunidade para verificar, não mais na escala do dêmos, e sim da pólis

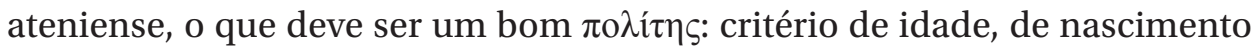
(= de reconhecimento paterno), casamento legítimo dos pais, condição de

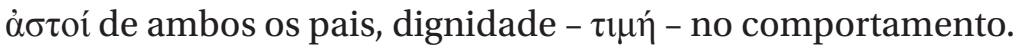

A formação da cidadania tem como fundamento, dessarte, o reconhecimento social do pertencimento ao círculo dos legítimos, uma operação que é assentada, inicialmente, na declaração de bom nascimento pelo pai, diante dos próximos. A cidadania é inicialmente praticada, para meninas e meninos, nos círculos de parentesco e, em seguida, no das assembleias, unicamente no caso dos homens. A cidadania é política para todos, na medida em que há discriminação entre filhos legítimos - meninas e meninos - e filhos ilegítimos. As mulheres que são fruto desses nascimentos são ả $\sigma \tau \alpha i ́$ (membros da pólis/cidade) e Ađqvaíat. Elas têm a condição de cidadãs, mas não exercem todas as funções cívicas: por serem mulheres, são excluídas do exército e das assembleias deliberativas e judiciárias e do sufrágio.

${ }^{34}$ Aristóteles, Constituição dos Atenienses, 26.4

${ }^{35}$ A questão dos "bastardos" é discutida pela tradição historiográfica desde fins do século XIX: Leduc (1994). Entendo a legitimidade como o reconhecimento social resultante dos procedimentos anteriores (declaração do pai, banquete das Apaturias e gamêlia). Deixo em suspenso a questão da criança nascida de dois astoi não casados (sem gamêlia). 
A delimitação do corpo de indivíduos autorizados a ter acesso aos ả $\chi \alpha$ í e à assembleia, por acréscimo ou supressão de $\pi \circ \lambda i ́ \tau \alpha$, é uma prática que atinge não somente os homens, como também as mulheres, posto que os critérios são, na maioria das vezes, critérios econômicos: dessarte, Clístenes teria introduzido, no corpo cívico, novos $\pi$ o $\lambda i ́ \tau \alpha$, dentre os quais, antigos excluídos da medida de 510 a.C. $;^{36}$ os oligarcas de 411 a.C. tentaram reservar o acesso às assembleias aos 5000 cidadãos mais ricos, dentre os 35000 contabilizados na pólis; os de 404 a.C. limitaram o acesso às assembleias a apenas 3000 homens; em 322 a.C., fez-se a proposta de reservar o acesso às assembleias aos detentores de um patrimônio de, no mínino, 2000 dracmas (menos da metade dos cidadãos do sexo masculino). Todas as medidas de exclusão dos mais pobres atingiam as famílias, e não só os cidadãos do sexo masculino. ${ }^{37}$

Aliás, pode-se ter certeza de que algumas mulheres são efetivamente politai quando se considera a questão das concessões de cidadania. São conhecidas concessões individuais (raras), às vezes, puramente honoríficas, e, sempre, em benefício de homens, apenas. Apolodoro, o sinégoro do discurso Contra Neera, por exemplo, é filho de um homem, Pasion, que obteve a cidadania por decreto do povo. Antigo escravo - liberto pelo seu dono, Arquestrato -, sábio banqueiro e empreendedor e marido de Archippê, ${ }^{38}$ Pasion ofereceu 1000 escudos provenientes de sua oficina à pólis, que o recompensou entre 394 e 376 a.C., concedendo-lhe a cidadania. Apolodoro, o filho de Pasion, pôde, então, se lançar numa carreira política. Propôs, em 346 a.C., uma campanha na Eubeia, contrariando a opinião de Demóstenes, que pedia ao povo uma campanha contra Filipe da Macedônia. A rivalidade política entre os dois concretizou-se no processo movido contra Apolodoro por Estéfano, amigo de Demóstenes e companheiro de Neera. Apolodoro replicou por meio do processo movido por Teomnesto, dado a conhecer pelo Contra Neera. Apolodoro, filho de escravo, é um $\pi$ o $\lambda i ́ \tau \eta \varsigma$ conhecido, cujo caso ilustra a possibilidade, para alguns homens, de ascensão social. Os raros beneficiários de concessões individuais de cidadania, no período clássico, nunca são mulheres. Porque? É tentador dizer que elas não têm a oportunidade de se destacar na guerra em prol da pólis, ou fazer uma doação importante, como Pasion pôde fazê-lo. Mas e se essa resposta fosse simples demais?

Quando de concessões coletivas de cidadania, pelo contrário, as mulheres são incluídas como beneficiárias implícitas. Em 429 a.C., quando a pólis de Plateias, vizinha à Beócia, foi atacada pelos tebanos e os espartanos, alguns plateenses se refugiaram em Atenas e se lhes concedeu, tanto a homens quanto a mulheres, a cidadania, por decreto. ${ }^{39} \mathrm{O}$ decreto indica que todos os privilégios

\footnotetext{
${ }^{36}$ Aristóteles, Política, III, 1275b36-37.

${ }^{37}$ Plutarco, Péricles 37.2.

${ }^{38}$ Caberia examinar o papel das esposas durante esses percursos. Archippê, esposa de Pasion, é mãe de Apolodoro e não há certeza de que tenha sido cidadã. Ver Mossé (2006).

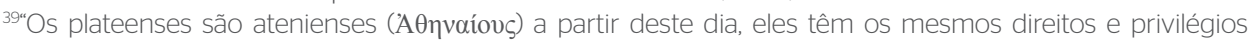

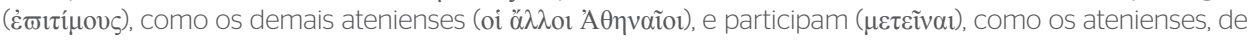
todas as atividades comuns, tanto as sagradas quanto as que são realizadas ritualisticamente" (Apolodoro, Contra Neera 104). Faz-se menção a essa concessão coletiva no §107, acima citado.
} 
dos cidadãos - toda a $\tau \mu \eta ́$ - lhes são concedidos: eles podem participar das atividades da $\pi$ ó $\lambda ı$, , em especial, dos assuntos sagrados e rituais, e são registrados nos dêmos e nas tribos (os homens iriam, portanto, às assembleias e se tornariam magistrados, podendo homens e mulheres participar dos atos coletivos da pólis ou do demos). Para o exercício do arcontado e dos sacerdócios, seria necessário esperar a geração seguinte, pelo menos, se os filhos nascessem "de uma mulher astê e oferecida em casamento de acordo com as regras". Em outras palavras, é a ateniense que transmite a condição política integral. Nos anos 429 a.C., a lei de Péricles relativa à dupla filiação não era muito aplicada (foi restaurada em 403 a.C.), ${ }^{40}$ sendo, portanto, bastante provável que muitas plateenses ou filhas de plateenses tenham podido progressivamente ingressar

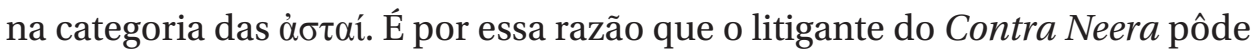
acrescentar, após ter mencionado que Neera não era uma $\dot{\alpha} \sigma \tau$, que, além do

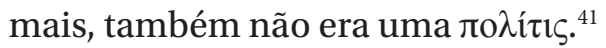

A riqueza do vocabulário da cidadania (pertencimento e participação nos assuntos públicos), declinado no masculino e no feminino, aponta que o fenômeno da cidadania não pode ser resumido a uma simples condição jurídica, que ficaria reservada aos atenienses de mais de 18 anos, após aprovação do povo.

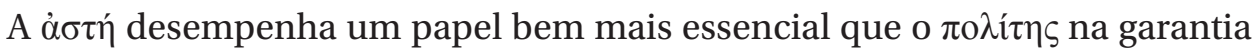
da condição dos indivíduos autorizados a participar das assembleias. Ela pode

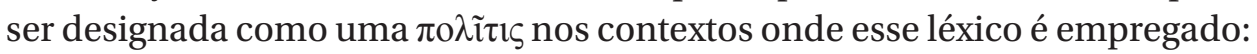
no século $\mathrm{V}$ a.C., para designar uma membro da pólis; no século IV a.C., para designar aquela que usufrui da $\pi 0 \lambda \imath \varepsilon \varepsilon i ́ \alpha$, ou seja, que é membro de um grupo de parentesco onde os homens adultos estão autorizados a participar das assembleias deliberativas e judiciárias. ${ }^{42}$ A complexidade daquilo que chamamos de cidadania antiga não resulta apenas, portanto, da variedade de denominações ou da variedade de funções que um ateniense pode ou não cumprir, nem da qualidade variável de sua dignidade ( $\tau \mu$ ) $)$, resultando, também, da articulação entre cidadãos, homens e mulheres, no dispositivo político.

\section{Renovar a abordagem do político?}

A partir do fim dos anos 1980, despontaram críticas, sem grandes ecos na França, ${ }^{43}$ onde a antropologia histórica estava tendo um grande sucesso intelectual e institucional e onde a tese da pólis, como clube de homens, coinci-

\footnotetext{
${ }^{40}$ Aristóteles, Constituição dos Atenienses, 27. 4; 42, 1; Plutarco, Péricles 37.4; Ateneu, Deipnosophistai, 577 b-c. 4l“'Essa mulher, pois, que se prostituiu em toda a Grécia e quis se passar por ateniense, ficaria impune, sendo que não é nem ateniense (astê) pelos seus ancestrais, nem cidadã (politis) por decisão do povo" (Apolodoro, Contra Neera 107).

${ }^{42}$ No século V a.C: Sófocles, Electra, 1227, e Eurípides, Electra, 1335; no século IV a.C:: Apolodoro, Contra Neera 104; Platão, Leis 814c; Aristóteles, Política, III, 1275-1278.

${ }^{43}$ Notar-se-á a perplexidade de Anne Jacquemin (2005, p. 337-338, nota 7), diante da pouca consideração dos argumentos convocados por Patterson (1987). De forma muito convincente, Patterson atentava para o fato de a noção de cidadania ser uma noção moderna, que tende a enviesar o debate ao aplicar, ao mundo antigo, categorias que lhe são estrangeiras. Os trabalhos conduzidos desde então a respeito dos pares privado/ público ou Estado/sociedade civil confirmaram como essas noções referiam-se a problemáticas relacionadas à história das sociedades ocidentais do século XIX (em última instância, ver Azoulay; Ismard [2007]).
} 
dia com a historiografia desenvolvida a respeito da França, como República de cidadãos. ${ }^{44}$ As críticas referiam-se a dois aspectos: por um lado, a elementos metodológicos relativos à seleção dos documentos escolhidos para sustentar a tese da exclusão das mulheres e, por outro, a simplificações nas análises lexicais referentes ao vocabulário da cidadania. Pode-se acrescentar que a definição do âmbito político, malgrado tentativas de abri-lo às práticas comunitárias que construíam a especificidade da atividade cívica, sempre encontrou dificuldades em sair do quadro das assembleias deliberativas e legislativas (deliberar, julgar, executar) e, portanto, em estendê-lo às cidadãs (Leduc, 1994). Contudo, até mesmo Claude Mossé, figura intelectual muito independente em relação à corrente historiográfica majoritária dos anos 1980-1990, tinha destacado que a cidadania antiga tinha essa especificidade de estar vinculada ao mundo dos deuses e deusas, além de depender das relações mantidas, por meio dos rituais, com ele. Em outras palavras, a noção de cidadania - e, por conseguinte, a noção de política - deveria levar em consideração esse aspecto característico das configurações sociais antigas, além da imbricação constante entre assuntos políticos e sociais e da preponderante posição ocupada pela religião. Nesta ótica, era importante destacar, segundo ela, "os limites da exclusão das mulheres no tocante à vida da pólis e à definição da cidadania" (Mossé, 1993, p. 61). ${ }^{45} \mathrm{Na}$ impossibilidade de encontrar um termo adequado, Claude Mossé utilizava o termo de "cidadania" feminina, usando aspas, como dissemos (Mossé, 1993, p. 64).

Vários trabalhos publicados nos anos 1980 e 1990 insistiram, com efeito, na participação ativa de muitas mulheres em atividades públicas coletivas, em especial, religiosas (por exemplo: Kron, 1996). A sacerdotisa de Athená Polias e a sacerdotisa de Deméter, por exemplo, tinham uma timê de primeio plano na pólis, bem mais eminente do que a de um simples cidadão, que só tinha acesso à assembleia. Lysimakè, cuja estátua, na Acrópole, foi vista por Pausânias, foi mãe e avó de cidadãos, falecendo com 88 anos, após ter sido sacerdotisa de Athená Polias durante 64 anos, no fim do século V e início do século IV a.C. (Georgoudi, 2003). Em suas funções, as cidadãs representavam toda a pólis; também representavam, portanto, os homens. ${ }^{46}$

A abordagem dessa historiografia consistia em examinar renovadamente as sociedades antigas, à moda dos etnólogos, com uma visão global das atividades coletivas (rituais, caça e banquetes, em especial [Polignac, 1981; Pantel, 1992a; Schnapp, 1997]), aumentando assim a distância entre nossa compreensão contemporânea do político e a praxe antiga. Afigurava-se claramente que a segmentação produzida hoje em dia entre as atividades religiosas - ou, de forma mais ampla, sociais - e as atividades "puramente" políticas (as assembleias

\footnotetext{
44Sobre a França como República de cidadãos, ver Nicolet (1976; 1982). Sobre a percepção da democracia ateniense, ver Mossé (2013).

${ }^{45} \mathrm{~A}$ especificidade da sociedade antiga e sua distância em relação às concepções sociais contemporâneas - em razão, sobretudo, da proeminência da religião - tinham sido amplamente realçadas, à época, por Coulanges (1872, p. 1-3).

${ }^{46}$ Sobre a importância dos rituais cívicos que envolvem a participação de mulheres (ou meninas), ver, em particular, Sourvinou-Inwood; Parker (2010).
} 
reservadas a alguns homens) poderia não ter sido uma segmentação pertinente na pólis antiga. Assim o afirmou Pauline Schmitt Pantel, em relação ao período arcaico (Pantel, 1987) ${ }^{47}$ Para estender essa tese ao período clássico, cabe, sem dúvida, introduzir a questão da transmissão das fontes e levar em conta o viés introduzido pela conservação dos escritos teóricos e políticos de Aristóteles, fontes que sempre exerceram domínio sobre a análise do político.

A reflexão foucautiana a respeito do poder acarretou, aliás, uma ampliação do âmbito de intervenção da arché, que, como se pôde demonstrar, era exercida tanto nas assembleias quanto nos santuários, quando de festas religiosas, e nas casas, acarretando, portanto, nesse mesmo movimento, uma matização da força obrigatória da lei (Foxhall, 1996; Just, 1989; Hunter, 1989).

\section{Vários trabalhos publicados nos anos 1980 e 1990 insistiram, com efeito, na participação ativa de muitas mulheres em atividades públicas coletivas, em especial, religiosas}

A volta a uma perspectiva mais materialista também permitiu lançar nova luz sobre as práticas econômicas e a importância do critério de riqueza na construção da democracia antiga, da participação política e da ideia de bem comum (Zurbach, 2013; Duplouy, 2014) ${ }^{48}$. Este último não é tanto um locus abstrato, cuja utilidade seria refletir sobre a partilha do poder; é, também, um território acaparado e compartilhado, da mesma forma que uma herança ou um animal sacrificado (Macé, 2014). O bem comum remete aos procedimentos de distribuição, que operam distinções e, não raro, uma hierarquização dos parceiros. Ora, as partilhas de bens sempre envolviam as mulheres, vetores da circulação de riquezas e das condições sociais (Leduc, 1991). As mulheres mais em vista pertenciam a famílias mais em vista; podiam agir como os homens em algumas esferas e nem sempre eram objetos passivos, a serem intercambiados entre homens necessariamente ativos. ${ }^{49}$ Destarte, a documentação menciona os nomes de tal ou tal mulher, que tinha emprestado ou arrendado terras; não havia, nessas práticas, qualquer desonra ou vergonha, e sim, tão

\footnotetext{
${ }^{47}$ Texto retomado e modificado por Pantel (1990; 1992b). Ver também o debate levantado em Pantel (2010), em especial, p. 389-390, onde Hansen expõe sua discordância: para ele, a democracia só tem um local, as assembleias.

${ }^{48}$ Duplouy, embore adote uma perspectiva totalmente diferente de Zurbach, atenta para o papel fundamental do critério de riqueza (em especial, fundiária) para a participação na política.

${ }^{49}$ No discurso de Demóstenes contra o seu tutor, descobre-se (contanto que o historiador faça o questionamento, atribuindo-lhe interesse) que foi Cleoboulê que administrou o patrimônio familiar após a morte de seu marido, um patrimônio cujas divisão e receitas foram apresentadas em detalhe ao filho. Ela cuidou da contabilidade; e esperava, do processo, o reembolso do dote de sua filha, para poder casá-la com outro (Contra Afobo, II, 21).
} 
somente, o interesse, corretamente entendido, do oikos. ${ }^{50}$ Mulheres e homens obedeciam, portanto, às mesmas lógicas e estratégias familiares, com vistas a obter maiores estima, riqueza e dignidade social. O caso dos recintos funerários familiares analisados por Daniela Marchiandi (2011) demonstra o mesmo para o século IV a.C. ateniense.

Por fim, a maior atenção dispensada às condições de produção dos documentos produzidos pelos antigos permite identificar alguns vieses de leitura. Em todas as fontes que estão à nossa disposição, a atividade dos tribunais e das assembleias encontra-se mais representada do que qualquer outra atividade pública, por razões relativas tanto ao prestígio dessa prática quanto à formação de uma literatura que memorizou e selecionou os discursos surgidos nesse contexto. É claro que, quando nos atrelamos ao período clássico, fundamental para a compreensão da genealogia da ideia moderna de cidadania, é essencialmente com base na pólis ateniense que a situação dos "antigos" ou, no melhor dos casos, dos "gregos" é apresentada. A norma que emerge desses documentos é uma divisão entre sexos complementares, com uma repartição dos espaços, tarefas e condições entre cidadãos e cidadãs, sendo que os homens se reservam às esferas das assembleias e da guerra. Para além desse escopo do exército, dos tribunais e das atividades das assembleias, a circulação de bens, o prestígio vinculado ao pertencimento familiar e a honra prestada a funções sociais reconhecidas (nomeadamente, a de sacerdotisa) envolvem a participação de homens e mulheres.

É o regime democrático que produz a cesura de gênero dentro do grupo dos participantes do dêmos, pois é o regime democrático que isola, dentre os membros da pólis, aqueles que participam das assembleias deliberativas e judiciárias. Nesse regime, a divisão dos sexos reforça ou, até mesmo, como o afirmava Nicole Loraux, funda uma sociedade que, partindo do ponto de vista das instituições políticas, constrói esferas (privado/pública; interior/exterior).

Esse ponto de vista define aquilo que designamos, em francês, desde 1927, como "o político", entendido como um conjunto de praxes diferentes do "social". ${ }^{51}$ Mas a prática cívica funcionava, factualmente, graças à inclusão do lado escondido do "político", ou seja, as cidadãs. A prática cívica funcionava junto a homens e mulheres para quem a divisão dos sexos, pertinente dentro da categoria dos cidadãos, desaparecia graças à sua solidariedade comum diante dos escravos, dos não cidadãos, dos membros de outra pólis e, talvez, dos ricos, quando se sentiam pobres, ou dos pobres, quando se sentiam ricos. Destarte, as cidadãs nunca foram uma classe à parte, nem tampouco foram percebidas pelos cidadãos como um grupo ameaçador ou reivindicativo. Às vezes, as mulheres, enquanto mães e esposas, enquanto parceiras sexuais e parceiras

\footnotetext{
50Ver, a esse respeito, os nomes de mulheres citados por Game (2008), Pernin (2004), Migeotte (2010) e Agut-Labordère; Veïsse (2014) e os estudos de Herfst (1979) e Brock (1994). Ver, também, Savalli (1983, p. 81-89), D’Ercole (2013) e Scheidel (1995).

${ }^{51} \mathrm{O}$ Dictionnaire historique de la langue française (Rey, 1998) indica s.v. "politique": "Adquire valor neutro (o político e o social) para designar o que diz respeito ao governo das sociedades (1927)".
} 
de filiação, excitaram a imaginação, o desejo ou o ódio dos homens, ${ }^{52}$ e não as cidadãs, enquanto tais. Na cidade grega clássica, o gênero não intervinha de forma unívoca: ele não a estruturava fundamentalmente, segundo uma divisão homem/mulher. Nas práticas cívicas, únicos lugares efetivos do político, operavam cidadãos e cidadãs. Essas práticas incluíam, para os primeiros, assembleias deliberativas e judiciárias e, para todos, os rituais comuns (incluindo o teatro), o intercâmbio de bens (terras, principalmente) e de pessoas (casamentos e adoções). Além disso, a arte de viver juntos concernia tanto essas pessoas quanto todos os demais - aqueles que residiam na pólis sem serem nem cidadãos, nem cidadãs.

\section{Referências bibliográficas}

AGUT-LABORDĖRE, Damien; VEÏSSE, Anne-Emmanuelle. Grecques et Egyptiennes dans les contrats de prêt aux IIIe et IIe siècles av. J.-C. In: TALLET, Gaëlle; ZIVIE-COCHE, Christiane. Le myrte \& la rose. Mélanges offerts à Françoise Dunand par ses élèves, collègues et amis, tomo 2. Montpellier: Université Paul Valéry, 2014, p. 415-423.

AZOULAY, Vincent (ed.). Annales. Histoire, Sciences Sociales, n. 2014/3, 2014a.

AZOULAY, Vincent (ed.). Repolitiser la cité grecque, trente ans après. Annales. Histoire, Sciences Sociales, n. 2014/3, p. 689-719, 2014 b.

AZOULAY, Vincent (ed.). Les Tyrannicides d'Athènes. Paris: Editions du Seuil, 2014c.

AZOULAY, Vincent; ISMARD, Paulin. Les lieux du politique dans l'Athènes classique. Entre structures institutionnelles, idéologie civique et pratiques sociales. In: PANTEL, Pauline Schmitt; BLOK, Josine. Becoming Citizens: Some Notes on the Semantic of Citizen in Archaic Greece and Classical Athens. Klio: Beiträge zur alten Geschichte, v. 87, p. 7-40, 2005.

BLOK, Josine. The priestess of Athena Nike: a new reading of $I G \mathrm{I}^{3} 35$ and 36. Kernos v. 27, p. 99-126, 2014.

BLOK, Josine. Citizenship, Cult and Community. Nova York: Cambridge University Press, no prelo. BROCK, Roger. The labour of Women in classical Athens. Classical Quaterly, v. 44, n. 2, p. 336346, 1994.

COHEN, Edward. The Athenian Nation. Princeton: Princeton University Press, 2000.

COULANGES, Numa Fustel de. La Cité antique. Etude sur le culte, le droit, les institutions de la Grèce et de Rome. Paris: Librairie Hachette, 1872.

CUCHET, Violaine Sebillotte. Touchée par le féminisme. L'Antiquité avec les sciences humaines. In: PAYEN, Pascal; SCHEID-TISSINIER, Évelyne (eds.). Anthropologie de l'Antiquité. Anciens objets, nouvelles approches. Turnhout: Brepols, 2012, p. 143-172.

D'ERCOLE, Cecilia. Marchands et marchandes dans la société grecque classique. In: BOEHRINGER, Sandra; CUCHET, Violaine Sebillotte (eds.). Des femmes en action. L'individu et la fonction en Grèce antique, Mètis H.S. Atenas; Paris: Éditions de l'Ehess, Daedalus, 2013, p. 53-71.

DEUBEL, Philippe; MONTOUSSÉ, Marc (eds.). Dictionnaire des sciences économiques et sociales. Rosny sous-Bois: Bréal, 2012.

DUPLOUY, Alain. Les prétendues classes censitaires soloniennes. A propos de la citoyenneté athénienne archaïque. Annales. Histoire, Sciences Sociales, n. 2014/3, p. 629-658, 2014.

FOXHALL, Lin. The Law and the Lady: Women and Legal Proceedings in Classical Athens. In: FOXHALL, Lin; LEWIS, Andrew D. E. (eds.). Greek Law in its Political Setting. Justifications not Justice. Oxford: Clarendon Press, 1996, p. 133-152.

\footnotetext{
${ }^{52}$ Pensa-se, aqui, é claro, nos discursos de Hesíodo (Teogonia, 531-616), ao Hipólito de Eurípides (Hipólito, 616650), ao poema de Semônides sobre a raça das mulheres (citado por Estabeu, a respeito do casamento: Florilégio, IV, 22, 193) ou aos versos de Aristófanes que veiculam clichês de gênero, sendo, como se pode observar, sempre produzidos em contextos sexuais.
} 
GABRIELSEN, Vincent. Profitable partnerships: Kings, cities, and trade. In: ARCHIBALD, Zobia H.; DAVIES, John K.; GABRIELSEN, Vincent (eds.). The Economies of Hellenistic Societies. Third to First Century BC. Oxford: OUP, 2011, p. 216-250.

GAME, Jean. Actes de vente dans le monde grec. Lyon: Maison de l'Orient et de la Méditerranée, 2008. GEORGOUDI, Stella. Lysimachê la prêtresse. In: LORAUX, Nicole (ed.). La Grèce au féminin. Paris: Les Belles Lettres, 2003, p. 167-214.

GHERCHANOC, Florence. L'oikos en fête. Célébrations familiales et sociabilité en Grèce ancienne. Paris: Publications de la Sorbonne, 2012.

GLOTZ, Gustave. Resenha de SZANTO, Emil. Das Griechische Bürgerrecht. Freiburg: Mohr, 1892. Revue Historique, tomo 54, fascículo 2, p. 394-406, 1894.

HERFST, Pieter. Le travail de la femme dans la Grèce ancienne. Nova York: Arno Press 1979.

HUNTER, Virginie. Women' Authority in Classical Athens. Echos du Monde classique. Classical Views, v. 8, n. 1. Calgary: University of Calgary, 1989, p. 39-48.

ISMARD, Paulin. Le simple corps de la cité. Les esclaves publics et la question de l'Etat grec. Annales. Histoire, Sciences Sociales, n. 2014/3, p. 723-751, 2014.

JACQUEMIN, Anne. Un autre conte de deux cités, ou Athéniennes et fières de l'être. Ktèma, n. 30, 2005, p. 337-347.

JUST, Robert. Women in Athenian Law and Life. Londres: Routledge, 1989.

KAMEN, Deborah. Full citizens: female. In: KAMEN, Deborah. Status in Classical Athens. Princeton: Princeton University Press, 2013a, p. 87-97.

KAMEN, Deborah. Status in Classical Athens. Princeton: Princeton University Press, 2013b. KRON, Uta. Priesthoods, dedications and euergetism. What part did religion play in the political and social status of Greek women? In: HELLSTRÖM, Pontus; ALROTH, Brita (eds.). Religion and Power in the Ancient Greek World. Uppsala: Acta Universitatis Upsaliensis, 1996, p. 139-182. LAMBERT, Sephane. The Phratries of Attica. Ann Arbor: The University of Michigan Press, 1996 LAUFER, Laurie; Rochefort, Florence (eds.). Qu'est-ce que le genre ? Paris: Payot/Rivages, 2014. LEDUC, Claudine. Comment la donner en mariage? La mariée en pays grec (IXème-IVème s. av. J.-C.). In: DUBY, Georges; PERROT, Michelle; PANTEL, Pauline Schmitt (eds.). Histoire des femmes en Occident. L'Antiquité. Paris: Plon, 1991, p. 259-316.

LEDUC, Claudine. Citoyenneté et parenté dans la cité des Athéniens, de Solon à Périclès. Mètis: Anthropologie des mondes grecs anciens, v. 9-10, p. 51-68, 1994.

LEDUC, Claudine. L'adoption dans la cité des Athéniens, VIe siècle-IVe siècle av. J.-C. Pallas, n. 48, p. 175-202, 1998a.

LEDUC, Claudine. La représentation aristotélicienne de la politeia de Solon: la politique 'dans' le domestique. Ktéma, n. 23, p. 415-422, 1998b.

LORAUX, Nicole. Le nom athénien. Les Enfants d'Athéna. Idées athéniennes sur la citoyenneté et la division des sexes. Paris: Editions La Découverte, 1981, p. 119-153.

LEDUC, Claudine. Héraklès: le surmâle et le féminin. In: LORAUX, Nicole. Les expériences de Tirésias. Le féminin et l'homme grec. Paris: Gallimard, 1989, p. 142-166.

LEDUC, Claudine. La cité divisée. L'oubli dans la mémoire d'Athènes. Paris: Editions PayotRivage, 1997.

LEDUC, Claudine. La Voix endeuillée. Essai sur la tragédie grecque. Paris: Gallimard, 1999.

LEDUC, Claudine. Corcyre, 427-Paris, 1871. In: LORAUX, Nicole. La tragédie d'Athènes. La politique entre l'ombre et l'utopie. Paris: Editions du Seuil, 2005, p. 31-60.

MACÉ, Arnaud. Deux formes du commun en Grèce ancienne. Annales. Histoire, Sciences Sociales, n. 2014/3, p. 659-688, 2014.

MARCHIANDI, Daniela. I periboli funerari nell'Attica classica: lo specchio di una 'borghesia'. Atenas/Pesto: Pandemos, 2011.

MIGEOTTE, Léopold. Affairisme féminin à la haute période hellénistique? In: Economie et finances publiques des cités grecques, $v$. 1. Choix d'articles publiés de 1976 à 2001. Lyon: Maison de l'Orient et de la Méditerranée, 2010, p. 248-257.

MOSSÉ, Claude. Le citoyen dans la Grèce antique. Paris: Editions Nathan, 1993.

MOSSÉ, Claude. Les esclaves banquiers à Athènes au IVe siècle avant J.-C. Une forme originale d'ascension sociale. In: COTTIAS, Myriam; STELLA, Alessandro; VINCENT, Bernard. Esclavage et dépendance serviles. Paris: L'Harmattan, 2006, p. 119-125.

MOSSÉ, Claude. L'idée républicaine en France: essai d'histoire critique (1789-1924). Paris: Gallimard, 1982. 
MOSSÉ, Claude. Regards sur la démocratie athénienne. Paris: Perrin, 2013.

MÜLLER, Christel. La (dé)construction de la politeia. Citoyenneté et octroi de privilèges aux étrangers dans les démocraties hellénistiques. Annales. Histoire, Sciences Sociales, n. 2014/3, p. 753-775, 2014.

NICOLET, Claude. Le métier de citoyen dans la Rome républicaine. Gallimard: Paris, 1976.

PANTEL, Pauline Schmitt. Les pratiques collectives et le politique dans la cité grecque. In: THÉLAMON, Françoise (ed.). Sociabilité, pouvoirs et société. Rouen: Université de Rouen, 1987, p. 279-288.

PANTEL, Pauline Schmitt. Collective Activities and the Political in Greek Cities. In: MURRAY, Oswyn; PRICE, Simon (eds.). The Greek City from Homer to Alexander. Oxford: Clarendon Press, 1990, p. 199-214.

PANTEL, Pauline Schmitt. La cité au banquet. Paris; Rome: École française de Rome, 1992a.

PANTEL, Pauline Schmitt. Les pratiques collectives et le politique dans la cité grecque. In: MURRAY, Oswyn; PRICE, Simon (eds.). La cité grecque d'Homère à Alexandre. Paris: Edition la Découverte, 1992b, p. 233-248.

PANTEL, Pauline Schmitt. Autour d'une anthropologie des sexes. À propos de la femme sans nom d'Ischomaque. Mètis: Anthropologie des mondes grecs anciens, v. 9-10, p. 299-305, 1994.

PANTEL, Pauline Schmitt. Démocratie athénienne, démocratie moderne: le rapport à la religion. In: HANSEN, Mogens H. Démocratie ancienne, démocraties modernes. Tradition et influences. Vandoeuvres-Genève: Fondation Hardt, 2010, p. 355-394.

PATTERSON, Cynthia. Hai Attikai: The other Athenians. In: Rescuing Creusa: new methodological approaches in antiquity. Helios, v. 13, n. 2, p. 49-67, 1987.

PERNIN, Isabelle. Les baux de Thespies (Béotie). Les hommes et la terre dans la Méditerranée gréco-romaine. Pallas, n. 64, p. 221-232, 2004.

POLIGNAC, François de. La naissance de la cité grecque. Paris: Edition la Découverte, 1981. REY, Alain (ed.). Dictionnaire historique de la langue française. Paris: Dicionários Le Robert, 1998. POLIGNAC, François de (eds.). Athènes et le politique. Dans le sillage de Claude Mossé. Paris: Albin Michel, 2007, p. 271-309.

OSBORNE, Robin. Women and Sacrifice in Classical Greece. In: Buxton, Richard (ed.). Oxford Readings in Greek Religion. Oxford: Oxford University Press, 2000, p. 294-313.

SAVALLI, Ivana. La donna nella società della Grecia antica. Bolonha: Patron, 1983.

SCHAPS, David M. The Woman Least Mentioned: Etiquette and Women's Names. The classical quaterly, v. 27, n. 2, p. 323-330, 1977.

SCHEIDEL, Walter. The Most Silent Women of Greece and Rome: Rural Labour and Women's Life in the Ancient World (I). Greece \& Rome, v. 42, n. 2, p. 212-217, out. 1995.

SCHNAPP, Alain. Le chasseur et la cité. Chasse et érotique dans la Grèce ancienne. Paris: Albin Michel, 1997.

SOURVINOU-INWOOD, Christiane; PARKER, Robert. Athenian Myths and Festivals: Aglauros, Erechtheus, Plynteria, Panathenaia, Dionysia. Oxford: Oxford University Press, 2010.

SZANTO, Emil. Das Griechische Bürgerrecht. Freiburg: Mohr, 1892.

TODD, Stephen C. Status and Gender in Athenian Public Records. In: THÜR, Gerhard; VELISSAROUPOULOS, Julie. Symposion 1995: Vorträge zur griechischen und hellenistischen Rechtsgeschichte. Colônia; Vienna: Bohlau, 1997, p. 113-124.

VIAL, Claude. Statut et subordination. In: CAVALIER, Odile (ed.). Silence \& Fureur. La femme et le mariage en Grèce. Avignon: Museu Calvet, 1996, p. 340-357.

VIDAL-NAQUET, Pierre. Esclavage et gynécocratie dans la tradition, le mythe, l'utopie. In: VIDAL-NAQUET, Pierre. Le chasseur noir. Formes de pensées et formes de société dans le monde grec. Paris: Editions La Découverte, 1991, p. 267-288.

WILL, Edouard. La Grèce archaïque. In: Second International Conference of economic history. Trade and Politics in Ancient World, v. 1. Nova York: M. I. Finley, 1979, p. 41-96.

ZURBACH, Julien. La formation des cités grecques. Statuts, classes et systèmes fonciers. Annales. Histoire, Sciences Sociales, n. 2013/4, p. 957-998, 2013. 